\title{
Evaluating Carrier Longevity Including Chemical/Microstructural Integrity for Extended Cycling: Effects of Atmosphere and Temperature on Particle Integrity
}

James Poston $^{1}$, Jarrett Riley ${ }^{2}$, Ranjani Siriwardane ${ }^{1}$, Nicole Kirby ${ }^{3}$ and Calaeb Houdshell ${ }^{2}$

${ }^{1}$ U.S. Department of Energy - NETL, Morgantown, West Virginia, United States, ${ }^{2}$ Oak Ridge Institute for Science Education (ORISE), Morgantown, West Virginia, United States, ${ }^{3}$ Leidos Research Support Team, Morgantown, West Virginia, United States

As part of a series of studies to determine the effects of extended cycling (50 - 1000 cycles), at different atmospheres and temperatures, has on the chemical structure, microstructure, and pellet morphology of existing manufactured oxygen carriers (OC), a progression of experiments utilizing Thermal Gravimetric Analysis (TGA) and Scanning Electron Microscopy/X-ray Microanalysis (SEM/XM) are in the process of being carried out. One of the experiments presently underway incorporates a unique wafer design which provides the ability to track specific particles imbedded in and/or on (Type-II and Type-I, respectively) the wafer for pre and post imaging and analysis, Figure 1. The primary particle properties under investigation are grain size distribution changes, void distribution changes, and phase segregation, with the goal of determining if particle steady state ever reached, what this comprises in terms of chemical and microstructural changes, and how this is impacted by phase controlling the reactive atmospheres such as fuel/soft oxidant ratios that limit reduction and coking effects. These particular series of experiments are being carried out utilizing a TA Instruments Q-50 TGA and a JEOL-840A SEM interfaced to a Noran NS$6 \mathrm{XM}$ system; image analysis is being carried utilizing ImageJ.

Initial experiments were carried out on type II and type I 500-600 um pellets of $\mathrm{CuFe}_{1.5} \mathrm{Al}_{0.5} \mathrm{O}_{4}$ at 800 ${ }^{\circ} \mathrm{C}\left(0{ }^{\circ} \mathrm{C}=273.15 \mathrm{~K}\right)$ in a $20 \% \mathrm{CH}_{4}$ - balance $\mathrm{Ar}$ environment, up to 200 cycles. Analyses of Type II $\mathrm{CuFe}_{1.5} \mathrm{Al}_{0.5} \mathrm{O}_{4}$ 500-600 um pellets, Figure 2, shows a non-linear decrease in particle grain diameter as well as a non-linear decrease in the size distribution of the particle grains with increased cycling. The corresponding Weibull distribution shows a non-linear increase with increased cycling indicating a narrowing of the partcle size distribution. The pore fraction of Type $\mathrm{II} \mathrm{CuFe}_{1.5} \mathrm{Al}_{0.5} \mathrm{O}_{4} 500-600$ um pellets increased non-linearly by approximetely $63 \%$ over 200 cycles. The observed decrease in particle dimater and increase in pore fraction with increased cycling correlates to observed increases in reactivity as a result of increased surafce area and decreased diffusion resistance. ${ }^{1}$ Increased attrition due to the decrease in particle density was also observed with increased cycling. ${ }^{2}$ Analyses of Type-I $\mathrm{CuFe}_{1.5} \mathrm{Al}_{0.5} \mathrm{O}_{4} 500$ 600 um pellets shows similar results to that of the Type-II $\mathrm{CuFe}_{1.5} \mathrm{Al}_{0.5} \mathrm{O}_{4} 500-600$ um pellets, with the particle grain size and size distribution of the particle grains decreasing non-linearly with increased cycling. The corresponding Weibull distribution also showed a non-linear increase with increased cycling. Similary, decreased particle diameter and increased pore fraction with increased cycling was observed with corresponding increased reactivity and increased attrition. 


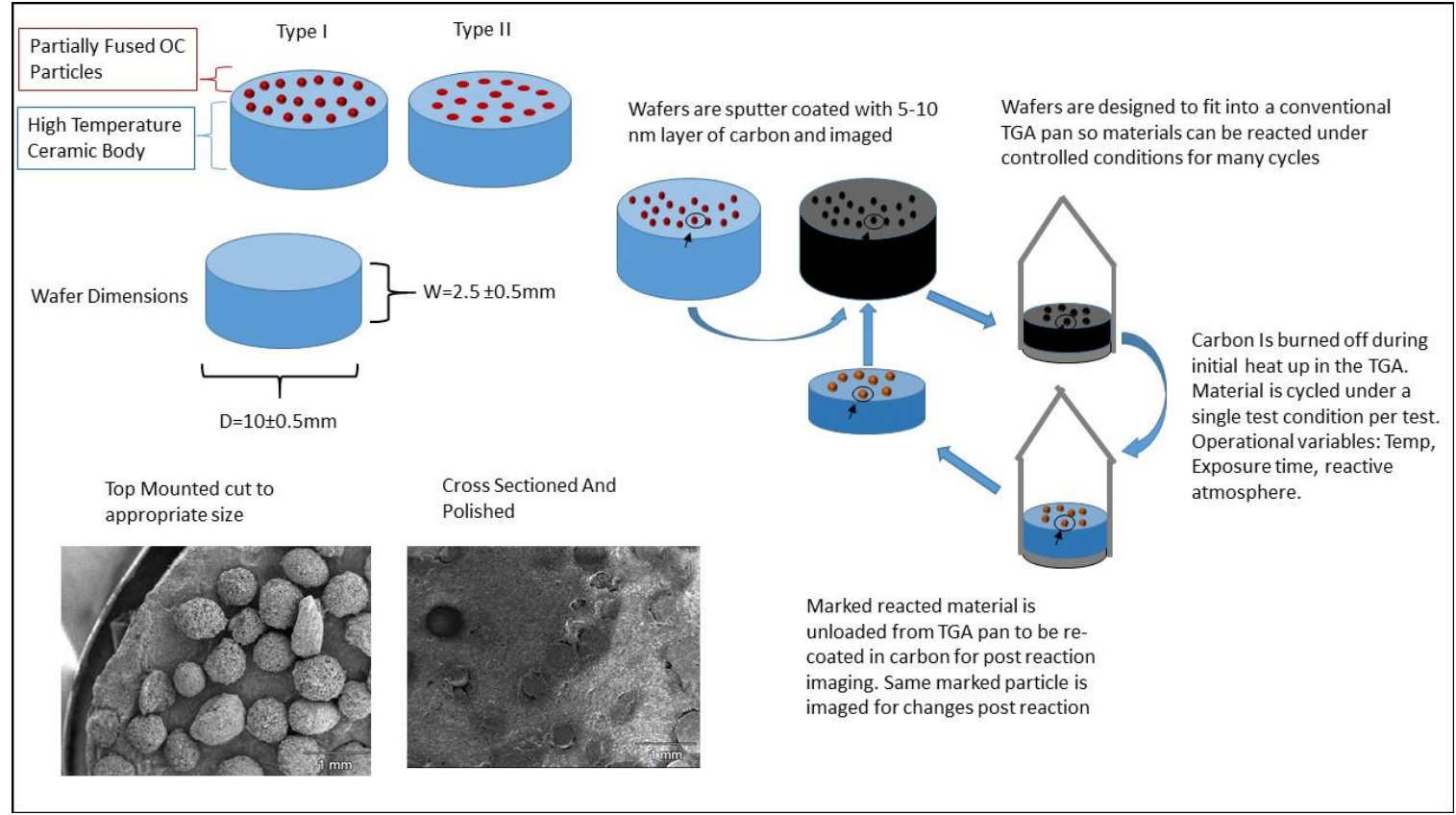

Figure 1. TGA-SEM Experimental Setup and Test Procedures

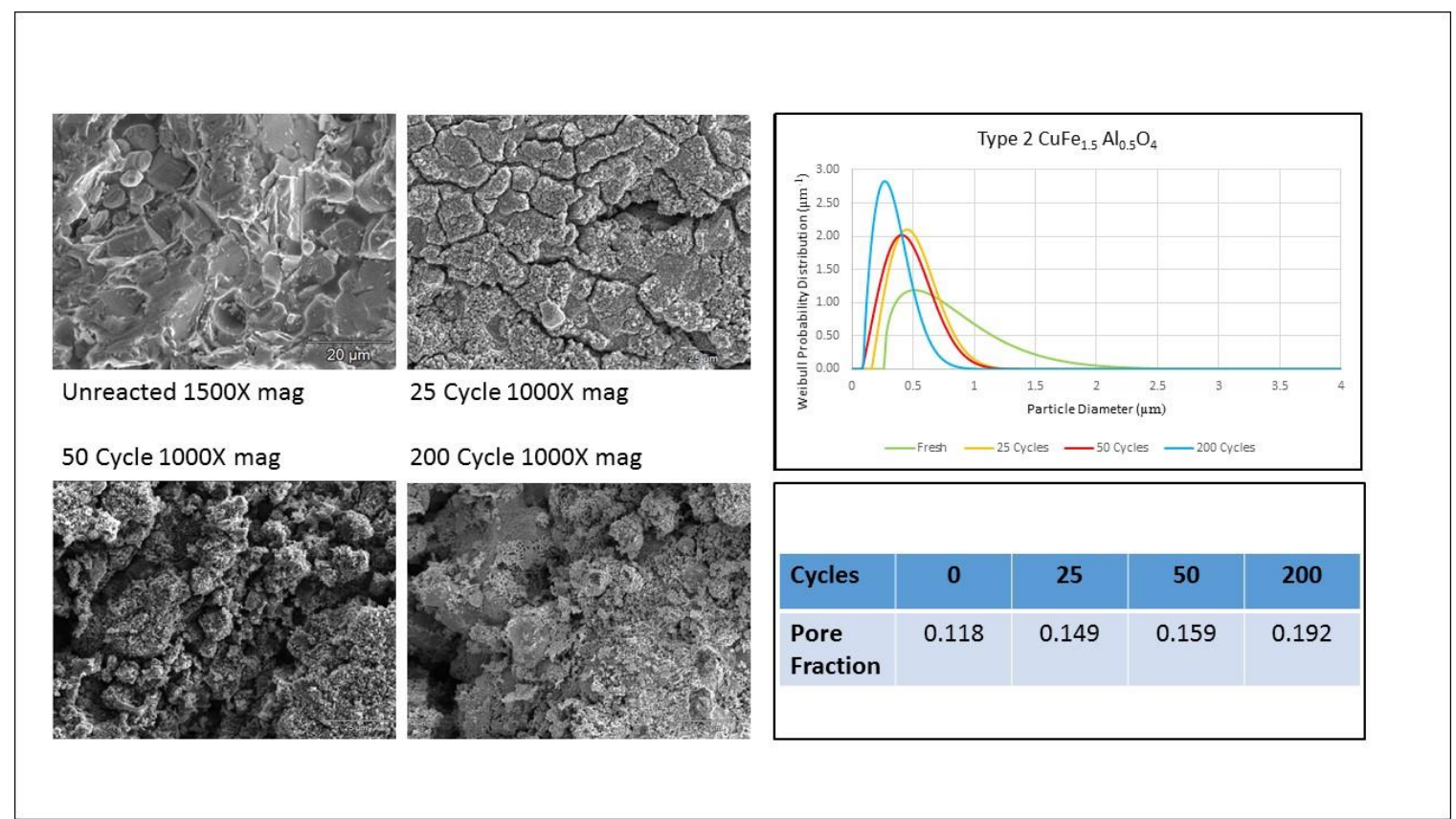

Figure 2. Type II CuFe1.5 Al0.5O4 Grain Size Distribution Changes due to Reactive Cycling

\section{References}

1. Chemical Reactions: Energy, Equilibrium, and Rate; Chapter 15, Chemistry: A Basic Introduction, Pages 293-312, G. Tyler Miller Jr., 1978, Wadsworth Publishing Company, Inc.

2. Strategies for Structured Particulate Systems Design; Chapter 19, Tools for Chemical Product Design, C. Amador and Martin de Juan, Computer Aided Chemical Engineering, Volume 39, 2016, Pages 509579. 